\title{
Obtaining insurance after DNA diagnostics: a survey among hypertrophic cardiomyopathy mutation carriers
}

\author{
Imke Christiaans ${ }^{\star, 1,2}$, Tjitske M Kok ${ }^{2}$, Irene M van Langen ${ }^{2}$, Erwin Birnie ${ }^{3}$, Gouke J Bonsel ${ }^{3}$, \\ Arthur AM Wilde ${ }^{1}$ and Ellen MA Smets ${ }^{4}$
}

\begin{abstract}
Hypertrophic cardiomyopathy (HCM) is a common hereditary heart disease associated with increased mortality. Disclosure of DNA test results may have social implications such as low access to insurance. In the Netherlands, insurance companies are restricted in the use of genetic information of their clients by the Medical Examination Act. A cross-sectional survey was used to assess the frequency and type of problems encountered by $\mathrm{HCM}$ mutation carriers applying for insurance, and associations with carriers' characteristics. The response rate was $86 \%$ (228/264). A total of 66 carriers (29\%) applied for insurance of whom 39 reported problems $(59 \%)$ during an average follow-up of 3 years since the DNA test result. More problems were encountered by carriers with manifest disease $(P<0.001)$ and carriers with symptoms of HCM $(P=0.049)$. Carriers identified after predictive DNA testing less frequently experienced problems $(P=0.002)$. Three carriers without manifest HCM reported problems $(5 \%$ of applicants). Frequently reported problems were higher premium (72\%), grant access to medical records $(62 \%)$, and complete rejection (33\%). In conclusion, HCM mutation carriers frequently encounter problems when applying for insurances, often in the case of manifest disease, but the risk assessment of insurance companies is largely justified. Still, $5 \%$ of carriers encounter potentially unjustified problems, indicating the necessity to monitor the application of the existing laws and regulations by insurance companies and to educate counselees on the implications of these laws and regulations.
\end{abstract}

European Journal of Human Genetics (2010) 18, 251-253; doi:10.1038/ejhg.2009.145; published online 12 August 2009

Keywords: hypertrophic cardiomyopathy; insurance; genetic testing

\section{INTRODUCTION}

Hypertrophic cardiomyopathy (HCM) is a hereditary heart disease affecting at least 1 in 500 persons worldwide. ${ }^{1,2} \mathrm{HCM}$ is manifest when a hypertrophied non-dilated left ventricle is present in the absence of other cardiac or systemic diseases that may cause cardiac hypertrophy. ${ }^{3,4}$ Patients with manifest HCM may remain asymptomatic, but HCM can also give rise to dyspnea, exertional angina, palpitations, and (pre)syncope. HCM patients have an increased risk of cardiovascular death, including sudden cardiac death (SCD, $1 \%$ per year) with excess mortality especially at young age. ${ }^{5}$ Relatives at risk can be identified by predictive DNA testing. Mutation carriers may develop $\mathrm{HCM}$ at any point in life and are therefore at increased risk for disease-associated death. In HCM, death due to heart failure or stroke is most likely related with the presence of manifest disease, that is, left ventricular hypertrophy. SCD, however, is caused by ventricular arrhythmias and it is not well determined whether mutation carriers without manifest disease are at increased risk for SCD.

DNA testing, especially in a predictive setting, may have negative social consequences, such as problems in obtaining access to insurance. ${ }^{6-10}$ This especially holds for insurance of which the premium or access is based on an individual risk assessment, like life and disability insurances. In the Netherlands, individual risk assessment can take into account current and past health, specific diseases that run in the family, and risk behavior (eg, smoking and sport activities). Such risk assessment is performed by insurance companies when an individual applies for a life, disability, individual pension, or additional health insurance. Basic (social) health insurance in the Netherlands is obligatory and the standard fixed premium is based on the average disease risk in the population.

Since 1990, Dutch insurance companies adhere to a moratorium on the use of DNA tests and genetic information in the application for specific insurances. In 1998, this moratorium was implemented by law in the form of the Medical Examination Act (MEA) to protect individuals who want to obtain a civil employment contract, a pension or a life or disability insurance. ${ }^{11}$ This act states that at the commencement or modification of an insurance below predefined sums ( $<€ 160000$ for life insurance and $<€ 32000$ for disability insurances in the first year and $<€ 22000$ in subsequent years) no questions may be asked about untreatable hereditary diseases or about the results of genetic tests for such diseases in the applicant and his/her relatives. An untreatable disease is defined as a disease without possibilities to treat, to prevent, or to inhibit its progression. Insurance companies are legally obliged to disregard available genetic test results for insurances below the predefined sums, except in case of manifest disease. Applicants in turn are legally obliged to report any manifest disease.

As HCM is an untreatable hereditary disease according to the MEA definition and problems in obtaining insurance have been previously reported by individual HCM mutation carriers, we wanted to assess:

${ }^{1}$ Department of Cardiology, Academic Medical Centre, Amsterdam, The Netherlands; ${ }^{2}$ Department of Clinical Genetics, Academic Medical Centre, Amsterdam, The Netherlands; ${ }^{3}$ Institute of Health Policy and Management, Erasmus Medical Centre, Rotterdam, The Netherlands; ${ }^{4}$ Department of Medical Psychology, Academic Medical Centre, Amsterdam, The Netherlands

${ }^{*}$ Correspondence: I Christiaans, Department of Clinical Genetics, Academic Medical Centre Amsterdam, Meibergdreef 9 , 1105 AZ Amsterdam, The Netherlands. Tel: +31 2056 65111; Fax: +31 2069 18626; E-mail: i.christiaans@amc.uva.nl

Received 22 April 2009; revised 7 July 2009; accepted 8 July 2009; published online 12 August 2009 
(1) how many HCM mutation carriers experience problems when applying for an insurance, (2) what type of problems they encounter, (3) which of these problems are most prevalent, and (4) whether problems are related to sociodemographic or clinical characteristics of the applicant.

\section{METHODS}

This cross-sectional study was performed in 2007-2008 at the cardiogenetics outpatient clinic of the Academic Medical Centre, Amsterdam, The Netherlands. All HCM mutation carriers counseled and tested for an autosomal dominant single pathogenic mutation at our outpatient clinic were invited to participate $(n=264)$. Participants had received their DNA test result at least eighteen months ago, had to master Dutch, and were at least 16 years of age.

The survey consisted of two questionnaires. Questionnaire I, part of a larger study, ${ }^{12}$ asked mutation carriers whether they had applied for insurances since their DNA test result and whether they had experienced any problems in this regard. Respondents who reported problems were invited to complete questionnaire II containing questions on the insurance sum, the nature of the problems, and the final application result. Both questionnaires were accompanied by an explanatory letter and a reply-paid envelope. After 2 weeks, all counselees received a reminder.

The results of the questionnaires are presented using descriptive measures (mean, SD). Univariate associations between carriers' sociodemographic and clinical characteristics and presence of insurance problems were tested using $\chi^{2}$-tests, Fisher exact tests, and $t$-tests, as appropriate.

\section{RESULTS}

Of the 264 initial questionnaires, 228 (86\%) were returned. Mean ( \pm SD) age of respondents was $49 \pm 15$ years, $49 \%$ were men and $59 \%$ had manifest HCM (Table 1). Since their DNA test result (mean ( \pm SD) time $3.3 \pm 1.4$ years), 66 mutation carriers (29\%) had applied for one or more insurances of whom 39 (59\%) reported problems. In total, 88 applications were reported of whom 59 resulted in problems (67\%). Problems did not relate to the type of insurance $(P=0.055$, Table 2).

No associations were found between sociodemographic characteristics and experienced problems when applying for an insurance (Table 1). However, problems were more frequently encountered by applicants with manifest disease (left ventricular hypertrophy) $(P<0.001)$ and applicants with symptoms of HCM $(P=0.049)$ (Table 1). Problems were less frequently encountered by carriers who had undergone DNA testing in a predictive setting $(P=0.002)$.

Of the 39 mutation carriers who encountered problems, $26(67 \%)$ indicated that they wanted to receive questionnaire II and $21(81 \%)$ returned this questionnaire. Problems most frequently encountered by these respondents were the requirements (1) to pay a higher premium (76\%), (2) to grant insurance companies access to cardiological records $(62 \%)$ or to the DNA test results (5\%), and (3) of a medical examination (19\%). In 33\%, the application was completely rejected. Reasons for the extra requirements or rejection were (more than one answer possible): manifest HCM (58\%), carriership of a HCM mutation $(21 \%)$, the presence of another serious or chronic disease (16\%), the occurrence of DNA testing for HCM (11\%), family history (11\%), lifestyle (11\%), and an increased mortality risk (11\%). Reasons given for requirements were not significantly different from reasons given for rejection. In total, $44 \%$ of the carriers experiencing problems

Table 1 Sociodemographic and clinical characteristics of HCM mutation carriers and a comparison of mutation carriers applying for an insurance without and with experienced problems

\begin{tabular}{|c|c|c|c|c|c|c|c|}
\hline \multirow[t]{3}{*}{ Characteristics } & \multirow{2}{*}{\multicolumn{2}{|c|}{$\begin{array}{l}\text { All mutation carriers } \\
\qquad \mathrm{n}=228\end{array}$}} & \multicolumn{4}{|c|}{ Mutation carriers applying for an insurance } & \multirow[t]{3}{*}{ P-value } \\
\hline & & & \multicolumn{2}{|c|}{ Without problems $\mathrm{n}=27$} & \multicolumn{2}{|c|}{ With problems $\mathrm{n}=39$} & \\
\hline & $n$ & $\%$ & $\mathrm{n}$ & $\%$ & $\mathrm{n}$ & $\%$ & \\
\hline Age (mean (SD)) & $49.0(15.4)$ & & $42.6(13.8)$ & & $45.3(11.3)$ & & 0.413 \\
\hline Male & 112 & 49.1 & 10 & 37.0 & 23 & 59.0 & 0.132 \\
\hline Having children & 184 & 80.7 & 18 & 66.7 & 33 & 84.6 & 0.135 \\
\hline Partner & 192 & 84.2 & 22 & 81.5 & 34 & 87.2 & 0.729 \\
\hline \multicolumn{8}{|l|}{ Level of education } \\
\hline Low & 71 & 31.1 & 3 & 11.1 & 9 & 23.1 & 0.411 \\
\hline Medium & 102 & 44.7 & 12 & 44.4 & 17 & 43.6 & \\
\hline High & 55 & 24.1 & 12 & 44.4 & 13 & 33.3 & \\
\hline \multicolumn{8}{|l|}{ Ethnic background } \\
\hline Dutch & 224 & 98.2 & 27 & 100 & 38 & 97.4 & 1.000 \\
\hline Other & 4 & 1.8 & 0 & 0 & 1 & 0.6 & \\
\hline Physical comorbidity & 101 & 44.3 & 8 & 29.6 & 17 & 43.6 & 0.307 \\
\hline Clinical diagnosis of HCM & 135 & 59.2 & 14 & 51.9 & 36 & 92.3 & $<0.001$ \\
\hline Heart complaints & 59 & 25.9 & 9 & 33.3 & 23 & 59.0 & 0.049 \\
\hline \multicolumn{8}{|l|}{$S C D$ in family ${ }^{a}$} \\
\hline Yes & 120 & 53.1 & 20 & 74.1 & 21 & 53.8 & 0.058 \\
\hline No & 59 & 26.1 & 6 & 22.2 & 8 & 20.5 & \\
\hline Does not know & 47 & 20.8 & 1 & 3.7 & 10 & 25.6 & \\
\hline Years since DNA test result (mean (SD)) & $3.3(1.4)$ & & $3.5(1.0)$ & & $3.9(1.5)$ & & 0.290 \\
\hline DNA test in predictive setting & 123 & 53.9 & 14 & 51.9 & 6 & 15.4 & 0.002 \\
\hline
\end{tabular}

HCM, hypertrophic cardiomyopathy; SCD, sudden cardiac death. $P$-values $<0.05$ are in bold text.

aUnknown in two mutation carriers. 
Table 2 Applications for insurance $(n=88)$ by $66 \mathrm{HCM}$ mutation carriers

\begin{tabular}{lrrr}
\hline Insurance application & \multicolumn{2}{c}{ Problems } & P-value \\
& Yes $(\mathrm{n}=59)$ & No $(\mathrm{n}=29)$ & \\
\hline Life insurance & 26 & 10 & \\
Disability insurance & 12 & 0 & \\
Pension & 4 & 1 & 0.055 \\
Surviving relatives' pension & 3 & 13 & \\
Changing health insurance & 9 & 3 & \\
Funeral insurance & 4 & 0 & \\
Other & 1 & & \\
\hline
\end{tabular}

HCM, hypertrophic cardiomyopathy.

when applying for a life insurance and $33 \%$ of the carriers experiencing problems when applying for disability insurance applied for insurance below the predefined sums stated in the MEA.

According to the MEA, unjustified requirements can only be made in mutation carriers without manifest HCM who apply for insurance below the predefined sum. Three carriers without manifest disease experienced problems applying for insurance. At least in one carrier unjustified requirements were made and possibly in another carrier (in the latter case the insurance sum was unknown); in total $1.5-3 \%$ of all applicants.

\section{DISCUSSION}

Despite legal restrictions on the use of genetic test results in insurance applications, HCM mutation carriers in the Netherlands frequently encounter problems when applying for insurances. During the 3 years of follow-up since disclosure of the DNA test result, a substantial part of the mutation carriers (29\%) applied for insurances and 59\% of them experienced problems. Most problems were reported by mutation carriers with manifest disease, a group known to be at increased risk of cardiovascular death. As the MEA requires applicants to report manifest disease, insurance companies' risk assessment is judged to be correct in most carriers.

In total, $33-44 \%$ of the respondents reporting problems applying for a life and/or disability insurance applied for insurance below the predefined sum of the MEA. Most of them had manifest disease and they were therefore legally obliged to report their disease irrespective of the insurance sum. However, problems were also reported by three carriers without manifest disease ( $5 \%$ of applicants). This is worrisome because there is no clear evidence for an increased mortality risk in these individuals. In at least one of them (and possibly in two) additional requirements were also unjustified according to the MEA, as the insurance sum applied for was below the predefined sums of questioning.

The insurance problems encountered by these three carriers without manifest disease could be due to an incorrect risk assessment by the insurance company. However, these problems may also result from carriers having difficulties filling in the insurance companies' health questionnaires. The line of questioning in these questionnaires is often unclear, and genetic risks and family history are often addressed regardless of the predefined sum. Although genetic counseling also addresses insurance issues, particularly in case of predictive DNA testing, it is unknown to what extent counselees are familiar enough with the MEA and act accordingly when filling in insurance companies' health questionnaires. The statement in questionnaires that insurance coverage is lost when incorrect information is provided may result in an over-response, although law does not require this.
Our data might underestimate the true frequency of additional requirements for insurance, as not all mutation carriers may experience a medical examination or access to medical records as a problem. On the other hand, the experienced problems reported by our carriers might not be classified as 'problems' from the perspective of the MEA. Higher premiums can be expected in mutation carriers with manifest disease and are in agreement with the law.

In summary, our data suggest that insurance companies' risk assessment of HCM mutation carriers is most often correct (95\%); additional requirements and rejection mainly occur in carriers with manifest disease who are known to be at an increased mortality risk. Nevertheless, some individuals encountered potentially unjustified problems (5\%). Therefore, we propose that application of the existing laws and regulations on the use of genetic information by insurance companies should be monitored. Secondly, individuals who attend a clinical genetics clinic for predictive DNA testing for untreatable disorders should always be informed about existing laws and regulations, and the possibility of insurance problems.

\section{CONFLICT OF INTEREST}

The authors declare no conflict of interest.

\section{ACKNOWLEDGEMENTS}

Clinical data of the HCM mutation carriers in this study are lodged in the GENCOR database (http//:www.gencor.nl), a national database for familial heart diseases, supported by the Interuniversity Cardiology Institute of the Netherlands. This research is financially supported by ZorgOnderzoek Nederland (ZonMw), grant number 62000010 and the Netherlands Heart Foundation (NHS), grant number 2003 D302. The funding organisations have had no involvement in study design, collection, analysis, and interpretation of data; in the writing of this paper and in the decision to submit the paper for publication.

1 Maron BJ, Gardin JM, Flack JM, Gidding SS, Kurosaki TT, Bild DE: Prevalence of hypertrophic cardiomyopathy in a general population of young adults. Echocardiographic analysis of 4111 subjects in the CARDIA Study. Coronary Artery Risk Development in (Young) Adults. Circulation 1995; 92: 785-789.

2 Morita H, Larson MG, Barr SC et al: Single-gene mutations and increased left ventricular wall thickness in the community: the Framingham Heart Study. Circulation 2006; 113: 2697-2705.

3 Elliott P, Andersson B, Arbustini E et al: Classification of the cardiomyopathies: a position statement from the European Society of Cardiology Working Group on Myocardial and Pericardial Diseases. Eur Heart J 2008; 29: 270-276.

4 Maron BJ, Towbin JA, Thiene G et al: Contemporary definitions and classification of the cardiomyopathies: an American Heart Association Scientific Statement from the Council on Clinical Cardiology, Heart Failure and Transplantation Committee; Quality of Care and Outcomes Research and Functional Genomics and Translational Biology Interdisciplinary Working Groups; and Council on Epidemiology and Prevention. Circulation 2006; 113: 1807-1816.

5 Elliott PM, Gimeno JR, Thaman R et al: Historical trends in reported survival rates in patients with hypertrophic cardiomyopathy. Heart 2006; 92: 785-791.

6 Godard B, Raeburn S, Pembrey M, Bobrow M, Farndon P, Ayme S: Genetic information and testing in insurance and employment: technical, social and ethical issues. Eur J Hum Genet 2003; 11 (Suppl 2): S123-S142.

7 Low L, King S, Wilkie T: Genetic discrimination in life insurance: empirical evidence from a cross sectional survey of genetic support groups in the United Kingdom. BMJ 1998; 317: 1632-1635

8 Marang-van de Mheen PJ, van Maarle MC, Stouthard ME: Getting insurance after genetic screening on familial hypercholesterolaemia; the need to educate both insurers and the public to increase adherence to national guidelines in the Netherlands. J Epidemiol Community Health 2002; 56: 145-147.

9 Raithatha N, Smith RD: Disclosure of genetic tests for health insurance: is it ethical not to? Lancet 2004; 363: 395-396.

10 Van Hoyweghen I, Horstman K: European practices of genetic information and insurance: lessons for the Genetic Information Nondiscrimination Act. JAMA 2008; 300: 326-327.

11 Medical Examination Act: Journal of the State (in Dutch) 1997; 636-642.

12 Christiaans I, van Langen IM, Birnie E, Bonsel GJ, Wilde AA, Smets EM: Quality of life and psychological distress in hypertrophic cardiomyopathy mutation carriers: a crosssectional cohort study. Am J Med Genet A 2009; 149A: 602-612. 